\title{
Nutritional deficiencies and fatty acid metabolism
}

\author{
By W. M. F. Leat, Agricultural Research Council, Institute of Animal \\ Physiology, Babraham, Cambridge CB2 $4 A T$
}

\section{Lipids}

The presence of lipid in the diet is not essential for the deposition of body fat, and proof that dietary carbohydrate is an important source of depot fat was first provided by Lawes \& Gilbert (1860, 1877). In pigs reared on diets virtually deficient in fat, the total amount of carcass fat is similar to that in animals fed isoenergetic diets containing $100 \mathrm{~g}$ fat $/ \mathrm{kg}$ diet, indicating that extremes of dietary composition with regard to fat and carbohydrate have little effect on the total amount of fat deposited in the carcass (Leat et al. 1964).

These observations can now be explained by the activity of the lipogenic enzymes which undergo considerable changes in activity dependent on the dietary and hormonal state of the animal (Volpe \& Vagelos, 1976; Bloch \& Vance, 1977). The catalytic activity of acetyl-CoA carboxylase, which is involved in the first, and probably rate-limiting step in the biosynthesis of fatty acids depends on the aggregation of the enzyme; the polymeric form is active, the protomeric form inactive, with the ratio of the two forms dependent on the composition of the diet (Ashcraft et al. 1980). High carbohydrate and low fat diets increase the polymeric form of the enzyme whereas high fat diets and starvation increase the protomeric form.

The activity of the $\Delta 9$-fatty acyl-CoA desaturase responds to changes in diet in a similar way to that of the lipogenic enzymes. The activities of both fatty acid synthetase and $\Delta 9$-desaturase are stimulated by dietary carbohydrate and suppressed by dietary fat, but the $\Delta 6$-desaturase appears to be less affected by diet (Jeffcoat, 1979).

When animals are reared on diets low in fat the fatty acid composition of the depot fats will reflect the spectrum of fatty acids produced biosynthetically, as distinct from those derived from the diet. Thus, in the pig (Table $r$ ) the major fatty acids of endogenous fat are palmitic, stearic and octadecenoic acids, with the proportions of each fatty acid being dependent on the anatomical location of the fat depot (Leat et al. 1964). Linoleic and linolenic acids are present in only trace amounts since they are essential fatty acids and must be provided in the diet. Oddchain acids are also detected, indicating that synthesis from a three-carbon priming unit does occur, albeit to a minor extent. In the rat the major fatty acids of endogenous origin are more unsaturated than those found in the pig (Table I), suggesting that the $\Delta g$-desaturase is more active in rat tissues than in those of the pig. The depot fatty acids of the newborn ruminant, which are mainly of endogenous origin, are more akin to those of the pig (Table r). 
Table I. Depot fatty acids of endogenous origin in the pig, lamb and rat (\%)

\begin{tabular}{|c|c|c|c|c|c|c|}
\hline \multirow{3}{*}{$\begin{array}{l}\text { Fatty } \\
\text { acid }\end{array}$} & \multicolumn{4}{|c|}{ Pig } & \multirow{3}{*}{$\begin{array}{c}\begin{array}{c}\text { Lambs } \\
\text { (newborn) }\end{array} \\
\text { Perinephric }\end{array}$} & \multirow{3}{*}{$\begin{array}{c}\text { Rats } \\
\text { (fed on fat-free diets) } \\
\text { Perinephric }\end{array}$} \\
\hline & \multicolumn{2}{|c|}{ Subcutaneous } & \multirow[t]{2}{*}{ Intermuscular } & \multirow[t]{2}{*}{ Perinephric } & & \\
\hline & Outer & Inner & & & & \\
\hline $16: 0$ & 23.8 & $25 \cdot 1$ & $26 \cdot 3$ & $27 \cdot 0$ & $23 \cdot 3$ & 24.5 \\
\hline $16: 1$ & $4 \cdot 8$ & $3 \cdot 8$ & $3 \cdot 3$ & 3.6 & $3 \cdot 0$ & 13.9 \\
\hline 18:0 & I I $\cdot 7$ & 154 & 14.9 & $18 \cdot 0$ & $17 \cdot 0$ & 3.0 \\
\hline I 8:1 & 55.4 & $52 \cdot 3$ & 52.4 & 47.8 & $55 \cdot 2$ & $5^{6} \cdot 0$ \\
\hline $18: 2$ & 0.7 & 0.5 & 0.2 & 0.2 & $<0.5$ & 0.4 \\
\hline Others & 3.6 & $2 \cdot 9$ & 2.9 & $3 \cdot 4$ & $1 \cdot 0$ & $2 \cdot 2$ \\
\hline
\end{tabular}

When diets completely deficient in fat are given to animals, signs of essential fatty acid (EFA) deficiency appear. These were first characterized by Burr \& Burr (1929, 1930) who established the essentiality of linoleic acid and possibly linolenic acid. The parent members of the $\omega_{9}, \omega 6$ and $\omega_{3}$ series of fatty acids, oleic (r $8: 1$ ), linoleic ( $18: 2$ ) and linolenic ( $18: 3$ ) acids respectively, are metabolized by a common enzyme system of alternating desaturation and elongation to give a series of fatty acids of increasing length and unsaturation (Fig. 1 ; Mead, 1968). The fatty acids compete for the same enzyme system, the affinity being in the order I 8:3>I 8:2>18: I (Dhopeshwarkar \& Mead, I96I; Mohrhauer \& Holman, 1963). When diets are deficient in EFAs ( $18: 2$ and $18: 3$ ) the eicosatrienoic acid (20:309) derived from oleic acid accumulates in tissue lipids. The proportion of arachidonic acid $(20: 4 \omega 6)$ declines and the ratio of $20: 3 \omega 9 / 20: 4 \omega 6$ therefore increases, and is often used as an indicator of EFA status with regard to $18: 2$, with ratios above 0.4 being indicative of an insufficiency of linoleic acid (Holman, 1960).

The minimum requirement for linoleic acid in most species is between $\mathrm{I}$ and $2 \%$ of the dietary energy (Holman, 1968), although recommendations for man are somewhat higher (FAO, 1978). Elevated ratios of 20:3/20:4 in plasma lipids are found in infants reared on milk diets containing less than $\mathrm{r} \%$ of the dietary energy as linoleic acid (Hansen et al. $19^{6} 3$ ) and in children suffering from protein-energy malnutrition (Naismith, 1973; Holman et al. 1981). One of the defects in malnutrition could therefore be a moderate EFA deficiency, resulting from a low intake of linoleic acid coupled with malabsorption caused by intestinal infections and overgrowth of bacteria in the upper intestine (James, 1977). However, a deficiency of protein may also be a contributory factor since, in the rat, an insufficiency of dietary protein or imbalances in amino acids can result in changes in lipid metabolism, leading to fatty infiltration of the liver, and an impairment of the enzyme system converting linoleic to arachidonic acid (Williams \& Hurlebaus, 1966).

Elevated ratios of 20:3 $\omega 9 / 20: 4 \omega 6$ in tissue lipids can also occur under normal husbandry conditions, for example, in the new-born ruminant (Leat, 1966). The 


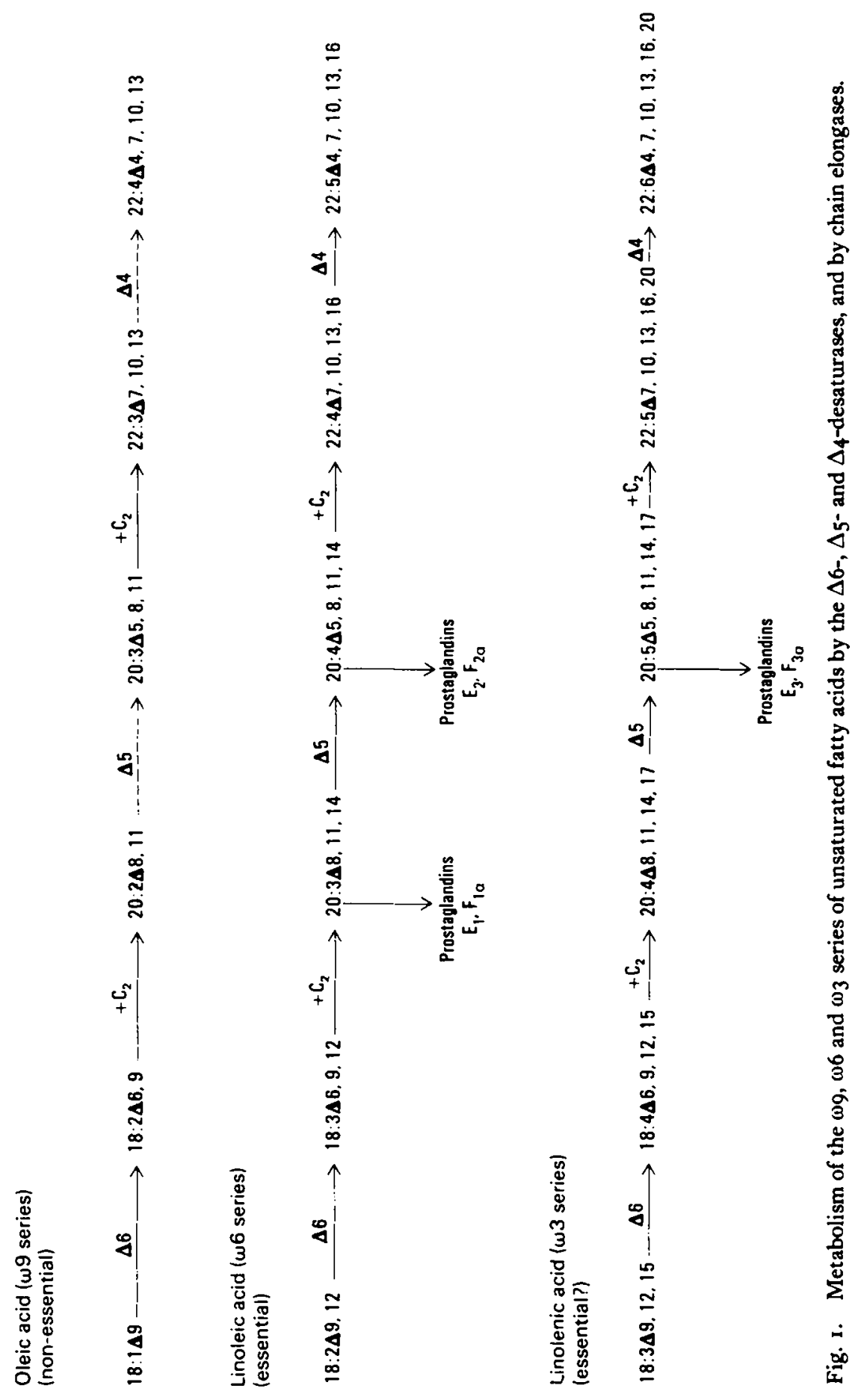


sheep placenta is virtually impermeable to the fatty acids of the maternal circulation (Leat \& Harrison, I980) and insufficient linoleic acid passes through the placenta to prevent the appearance of 20:3 109 in foetal tissues. In adult ruminants, only small amounts of essential fatty acids $(\angle \mathrm{r} \%$ of the dietary energy) reach the site of the small intestine (Leat \& Harrison, 1972) because of hydrogenation of dietary unsaturated fatty acids in the rumen, but no signs of EFA deficiency are found. The ruminant conserves the small quantities of EFA available to it by mechanisms which channel EFA into esterified lipid and hence reduce the chances of oxidation (Lindsay \& Leat, 1977 ).

When linoleic acid is the sole source of dietary EFA in rats, the concentration of derivatives of the $\omega_{3}$ series of fatty acids is reduced (Mohrhauer \& Holman, 1963 ) but some tissues, e.g. retina, retain the $\omega_{3}$ fatty acids tenaciously and are only depleted when the deficiency is continued into a second generation (Tinoco et al. 1977).

When linolenic acid is given to rats as a sole source of EFA, tissue lipids contain varying amounts of $\omega_{3}$ fatty acids at the expense of the $\omega 6$ fatty acids (Mohrhauer $\&$ Holman, 1963 ). However, $\omega_{3}$ fatty acids do not replace $\omega 6$ fatty acids in rat testis, which is probably a reflection of the degenerative changes occurring in the germinal epithelium (Leat et al. 1983 ). In female rats fed linolenic acid, the major physiological defect is an impairment in the process of parturition probably consequent upon the decreased levels of tissue arachidonic acid and hence reduced production of the prostaglandins involved in smooth-muscle contraction (Leat \& Northrop, 1981).

Carnivores appear to differ from other animals in having a very limited capacity to convert $18: 2 \omega 6$ to $20: 4 \omega 6$ because of the virtual absence in the tissues of the $\Delta 6$-desaturase and the relative inactivity of the $\Delta_{5}$-desaturase (Rivers et al. I 975 ; Sinclair et al. 1979). In the cat, $18: 2 \omega 6$ is chain-elongated to $20: 2 \omega 6$, which is converted by the $\Delta_{5}$-desaturase into an unusual eicosatrienoic acid $\left(20: 3 \Delta_{5}\right.$, I I, I4). Linoleic acid, therefore, has only partial EFA activity in carnivores. These animals require the addition to the diet of long-chain derivatives of the parent EFA to satisfy their requirements for EFAs.

\section{Water-soluble vitamins}

Many water-soluble vitamins are integral parts of coenzymes involved in intermediary metabolism, and might be expected to play important roles in fatty acid metabolism. For example, pantothenic acid is a component of coenzyme-A, the sulphydryl group of which confers solubility and high energy potential on the fatty acid molecule, thus activating otherwise weak acids and facilitating their metabolism. Nicotinamide is a component of NAD and NADP which are involved in hydrogen transfer and are important in the synthesis and degradation of fatty acids, carbohydrates and amino acids.

Thiamin (vitamin $B_{1}$ ). Thiamin, as its pyrophosphate ester (co-carboxylase), is a coenzyme for pyruvate dehydrogenase which converts pyruvate to acetyl-CoA, a fundamental building block for fatty acid synthesis; it is therefore important in the 
transformation of carbohydrates to lipids. Thiamin is also involved in the coenzyme for transketolase which is involved in the pentose phosphate pathway producing the $\mathrm{NADPH}_{2}$ required for fatty acid synthesis. Thiamin is important in maintaining the cellular integrity of the nervous system and the site of the early lesion of thiamin deficiency is the glial cell. Glial cells subjected to thiamin deficiency exhibited rates of fatty acid synthesis only $13 \%$ of that of controls (Volpe \& Marasa, 1978), the decreased lipogenesis presumably resulting from a relative lack of acetyl-CoA.

Riboflavin (vitamin $B_{2}$ ). Riboflavin in the form of flavin mononucleotide (FMN) or flavin adenine dinucleotide (FAD) acts as a coenzyme for flavin enzymes involved in $\mathrm{H}$ transfer. The earliest and most significant biochemical change found in riboflavin deficiency is a marked reduction in the ability of the animal to catabolize fatty acids in the mitochondrion by $\beta$-oxidation. Olpin \& Bates (1982) reported a reduction of approximately $50 \%$ in the oxidation of long-chain fatty acids and in the activity of acyl-CoA dehydrogenase. The dehydrogenation of acyl$\mathrm{CoA}$ is an important intermediate stage in the degradation of activated fatty acid by $\beta$-oxidation and is catalyzed by three enzymes containing FAD as their prosthetic group (Hoppel et al. 1979); this could explain the accumulation of lipid in the liver and the impaired oxidation of fatty acids indicated by the increased excretion of adipic, hexenedioic, suberic, octenedioic, sebacic and decenedioic acids in the urine of $B_{2}$-deficient rats (Goodman, 1981 ).

Biotin. Biotin is involved as the prosthetic group of a number of enzymes involved in carboxylation reactions. Pyruvate carboxylase catalyzes the conversion of pyruvate to oxaloacetate in the mitochondrion and is important in gluconeogenesis. Acetyl-CoA carboxylase, catalyzing the conversion of acetyl-CoA to malonyl-CoA is the first, and probably rate-limiting step in the synthesis of long-chain fatty acids in the cytoplasm. This enzyme plays a crucial role in the de novo synthesis of the fatty acids required for cell growth and replication. In vitro, the removal of biotin from the media results in a marked inhibition in the generation of cytotoxic lymphocytes that can be partly overcome by the addition of fatty acids (Kung et al. 1979). Propionyl-CoA carboxylase catalyzes the conversion of propionyl-CoA to methylmalonyl-CoA which can either enter the citric acid cycle after conversion to succinate and then oxaloacetate, or enter the fatty acid synthetic pathway to form branched-chain fatty acids.

A marginal deficiency of biotin is involved in the fatty liver and kidney syndrome (FLKS) in chicks where there is fatty infiltration of many organs including liver and kidney (Wight \& Siller, 1975). However, these abnormalities in lipid metabolism are probably secondary changes arising from a failure of hepatic gluconeogenesis with resultant mobilization of large amounts of fatty acids from adipose tissue and transfer to liver. When biotin availability in chicks is limited, the requirement for acetyl-CoA carboxylase appears to be satisfied at the expense of pyruvate carboxylase, thus reducing the production of glucose by gluconeogenesis (Whitehead \& Bannister, 1978; Bannister, 1979). The change in fatty acid composition of hepatic lipids in FLKS may merely represent the 
deposition of depot lipids, but the increased desaturase activity of liver may also contribute to the increased content of palmitoleic acid. The ratio of palmitoleic acid:stearic acid has been suggested as a predictive indicator for FLKS.

Pyridoxine. Pyridoxal phosphate is the major coenzyme form of pyridoxine and is involved mainly in the catabolism of amino acids via transaminases and decarboxylases. However, pyridoxal phosphate is also a cofactor in the biosynthesis of sphingosine (Brady \& Koval, 1958), and in pyridoxine-deficient animals the activity of the enzymes forming the very long chain fatty acids $\left(>\mathrm{C}_{20}\right)$ found in myelin appears to be impaired (Dakshinamurti, I982). In consequence, the myelin of pyridoxine-deficient rats is quantitatively and qualitatively different from that of normal rats.

There are similarities between the syndrome of pyridoxine deficiency and that of essential fatty acid deficiency, and Witten \& Holman (1952) have suggested that pyridoxine is involved in the conversion of linoleic to arachidonic acid and linolenic to docosahexaenoic acid. However, more recent evidence indicates that pyridoxine may have a more general role in the metabolism of fatty acids (Kirschman \& Coniglio, 196r; Dussault \& Lepage, 1979).

Inositol. Inositol is located in cell membranes in the form of phosphatidylinositol which is involved in the regulation of enzyme activity and in the response of the cell to various stimuli. The major fatty acids are stearic acid, and arachidonic acid which is released under the action of phospholipase $A_{2}$ and made available for prostaglandin synthesis.

Inositol is a lipotropic factor and in deficiency states an accumulation of lipid occurs in the liver, partly as a result of impaired transport of lipoprotein from liver to plasma combined with increased fatty acid mobilization from adipose tissue resulting from an activation of hormone-sensitive lipase (Holub, 1982). In inositol deficiency there is also an increased rate of synthesis of two key lipogenic enzymes in the liver, fatty acid synthetase and acetyl-CoA carboxylase, and this may account for part of the lipid accumulation noted in inositol deficiency (Beach \& Flick, 1982).

Choline. Choline is a precursor in the biosynthesis of phospholipids which are important in maintaining the integrity of cell membranes (Zeisel, 1981). Choline deficiency results in fatty infiltration of the liver in many species, probably a consequence of disturbance in the ability of the hepatocytes to secrete lipid secondary to faulty biosynthesis of plasma lipoproteins.

Vitamin $B_{12}$ (and cobalt); folic acid. In herbivores, deficiences of vitamin $B_{12}$ and of cobalt are interrelated since $C o$ is an integral part of the $B_{12}$ molecule which is synthesized by gut flora either in the rumen or in the large intestine. Vitamin $B_{12}$ is involved in at least two enzyme systems, namely (i) methyl transferase involved in methionine biosynthesis and (ii) methylmalonyl-CoA mutase involved in the transformation of methylmalonyl-CoA to succinate.

Vitamin $B_{12}$ deprivation results in altered fatty acid metabolism in man and other animals. There is an increase in tissue concentrations of propionic acid and methylmalonic acid which are utilized in fatty acid synthesis and result in an 
increased content of odd-chain and branched-chain fatty acids in some tissue lipids (Garton, 1975; Akesson et al. 1979). In the liver and adipose tissue of Co-deficient lambs, there are increased proportions of odd-chain fatty acids resulting from the increased availability of propionic acid (Duncan et al. 1981). Vitamin $B_{12}$ deprivation may also interfere with the conversion of the EFAs to their longer chain polyunsaturated derivatives (Peifer \& Lewis, I979). The elevated levels of methylmalonyl-CoA in $B_{12}$ deficiency will tend to inhibit the biosynthesis of malonyl-CoA required for the elongation of fatty acids.

Folic acid is involved, together with choline and vitamin $B_{12}$, in the supply and transfer of methyl groups, and there is an overlap in the pathophysiology of folate and vitamin $B_{12}$ deficiencies. In folate deficiency there is a fatty infiltration of the liver with increased proportions of ethanolamine phosphoglyceride at the expense of choline-phosphoglyceride, probably resulting from a decreased availability of Sadenosylmethionine caused by the low concentration of methylated folic acid in the liver (Akesson et al. I 982).

\section{Fat-soluble vitamins}

Vitamin $\mathrm{E}$ ( $\alpha$-tocopherol) is an excellent antioxidant and functions in vivo as a scavenger of free radicals (Tappel, 1962). The rate of peroxidation varies with the extent of unsaturation of the fatty acids, and membranes containing high levels of polyunsaturated fatty acids (PUFA), e.g. in mitochondria, microsomes and retina, are very susceptible to oxidation. The cellular accumulation of lipofuscin with age may be a consequence of the peroxidation of membrane fatty acids (Tappel et al. 1973; Katz et al. 1978).

The requirement for vitamin $\mathrm{E}$ is largely governed by the amount of PUFA in the diet, particularly in young animals (Blaxter, 1962; Horwitt, 1972; Witting, 1974), and a level of $0.6 \mathrm{mg} \alpha$-tocopherol/g PUFA in the diet has been suggested as a suitable ratio of the two nutrients (Harris \& Embree, 1963 ).

In vitamin $\mathrm{E}$ deficiency, degeneration of the testis occurs with a two-fold increase or more in the proportion of arachidonic $(20: 4 \omega 6)$ and docosatetraenoic $(22: 4 \omega 6)$ acids in testicular lipids and a reduction in that of docosapentaenoic acid

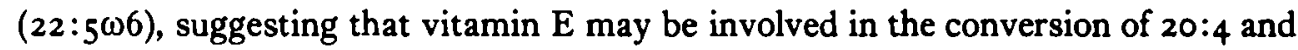
$22: 4$ to $22: 5$, or in the regulation of the formation of 20:4 (Bieri \& Prival, 1966).

Selenium can prevent some of the signs of vitamin E deficiency, and a complex relationship exists between these two nutrients (Combs et al. 1975; Hoekstra, 1975). Se is an integral component of the enzyme glutathione peroxidase, which is important in destroying hydrogen peroxide, and for converting damaging lipid hydroperoxides into alcohols and thus guarding the cell membrane against oxidative damage. The oxidation of EFAs in deficiencies of vitamin $\mathrm{E}$ and $\mathrm{Se}$ results in an increased content of ethane and pentane in exhaled air (Kivits et al. 198I).

In retinol deficiency there are changes in the PUFA of testicular lipids (Bieri \& Prival, 1966), but these changes may be merely a reflection of the degeneration occurring in the germinal cells. 


\section{Minerals}

Zinc. Zinc, an essential trace metal, is a structural component of many enzymes and appears to play a specific role in NADPH metabolism (Chvapil et al. 1975). Many of the signs of $\mathrm{Zn}$ deficiency are similar to those of EFA deficiency, e.g. growth retardation, dermal lesions, testicular degeneration, lengthened gestation and impaired parturition (Underwood, 1977). These similarities, together with the observation that a deficiency of both $\mathrm{Zn}$ and EFA in rats exacerbates some of the separate deficiency signs (Bettger et al. 1979), suggests that $\mathrm{Zn}$ is involved in the metabolism of EFA, but the precise mode of action remains unclear.

In $\mathrm{Zn}$ deficiency there is an increase in the proportion of arachidonic acid in skin (Bettger et al. 1979), testis (Bieri \& Prival, I966), plasma and liver (Cunnane et al. 1981), again suggesting the involvement of $\mathrm{Zn}$ in the metabolism of EFAs, possibly at the $\Delta 6$-desaturation stage or in their conversion to prostaglandins. The precise relationship between $\mathrm{Zn}$ and the $\Delta 6$-desaturase is not clear and may vary between tissues; for example, in the mammary gland the activities of the $\Delta 6$ - and possibly $\Delta 9$-desaturases are increased in $\mathrm{Zn}$ deficiency (Cunnane \& $\mathrm{Wahle,}$ 1981) whereas in testis both $\Delta 6$ - and $\Delta_{5}$-desaturase activities are decreased (Clejan et al. 1982).

The suggestion that $\mathrm{Zn}$ is involved in the regulation of prostaglandin metabolism receives some support from the observation that pregnant rats suffer impaired parturition when given either $\mathrm{Zn}$-deficient diets or when dosed with aspirin, a potent prostaglandin synthetase inhibitor (O'Dell et al. 1977). The impairment of parturition may be a consequence of altered prostaglandin synthesis from arachidonic acid in the uterine wall and placenta, resulting in hypocontractability of the uterine wall and decreased placental blood flow (Cunnane, ig82).

Copper. Copper has a growth-stimulating effect in pigs which is sometimes accompanied by a softening of adipose tissue (Taylor \& Thomke, 1964). This softening of body fat is partly the result of an increased ratio of $\mathrm{C}_{18}$ monoenoic acids:saturated $\mathrm{C}_{18}$ fatty acids, suggesting an increased activity of $\Delta 9$-desaturase activity. Cu deficiency in the rat is associated with a decreased ratio of monounsaturated:saturated fatty acids in subcutaneous tissue and a decreased activity of hepatic microsomes, again suggesting an involvement of $\mathrm{Cu}$ in the desaturase reaction, possibly in the terminal component of the microsomal electron transport chain (Wahle \& Davies, 1975).

\section{REFERENCES}

Akesson, B., Fehling, C. \& Jagerstad, M. (1979). Br. J. Nutr. 4I, 263.

Akesson, B., Fehling, C., Jagerstad, M. \& Stenram, U. (1982). Br. F. Nutr. 47, 505.

Ashcraft, B. A., Fillers, W. S., Augustine, S. L. \& Clarke, S. D. (I 980). F. biol. Chem. 255, 10033.

Bannister, D. W. (1 979). Int. J. Biochem. ro, 193.

Beach, D. C. \& Flick, P. K. (1982). Biochim. biophys. Acta $711,452$.

Bettger, W. J., Reeves, P. G., Moscatelli, E. A., Reynolds, G. \& O'Dell, B. L. (1979). J. Nutr. rog, 480 .

Bieri, J. G. \& Prival, E. L. (1966). J. Nutr. 89, 55 . 
Blaxter, K. L. (I g62). Vitams. Horm. 20, 633 .

Bloch, K. \& Vance, D. (1977). A. Rev. Biochem. 46, 263.

Brady, R. O. \& Koval, G. J. (1958). F. biol. Chem. $233,26$.

Burr, G. O. \& Burr, M. M. (1929). f. biol. Chem. 82, 345 .

Burr, G. O. \& Burr, M. M. (1930). F. biol. Chem. 86, $5^{87}$.

Chvapil, M., Sipes, I. G., Ludwig, J. C. \& Halladay, S. C. (1975). Biochem. Pharmac. 24, 917.

Clejan, S., Castro-Magana, M., Collipp, P. J., Jonas, E. \& Maddaiah, V. T. (1982). Lipids $17,129$.

Combs, G. E. Jr., Noguchi, T. \& Scott, M. L. (1975). Fedn Proc. Fedn Am. Socs exp. Biol. 34, 2090.

Cunnane, S. C. (1982). Br. F. Nutr. 47, 495.

Cunnane, S. C., Huang, Y. S., Horrobin, D. F. \& Davignon, J. (1981). Prog. Lipid Res. 20, 157.

Cunnane, S. C. \& Wahle, K. W. J. (1981). Lipids 16, 77 I.

Dakshinamurti, K. (1982). Adv. Nutr. Res. 4, 143.

Dhopeshwarkar, G. A. \& Mead, J. F. (1961). J. Am. Oil Chem. Soc. 38, 297.

Duncan, W. R. H., Morrison, E. R. \& Garton, G. A. (1981). Br. f. Nutr. 46, 337.

Dussault, P. E. \& Lepage, M. (1979). F. Nutr. rog, 138 .

FAO (1978). Food and Nutrition paper no. 3. Geneva: FAO.

Garton, G. A. (1975). Rep. Rowett Inst. 31, 124.

Goodman, S. I. (1981). Am. F. clin. Nutr. 34, 2434.

Hansen, A. E., Wiese, H. F., Boelsche, A. N., Haggard, M. E., Adam, D. J. D. \& Davis, H. (1963). Pediatrics 31, 171.

Harris, L. A. \& Embree, N. D. (1963). Am. F. clin. Nutr. 13, 285.

Hoekstra, W. G. (1975). Fedn Proc. Fedn Am. Socs exp. Biol. 34, 2083.

Holman, R. T. (1960). F. Nutr. 70, 405.

Holman, R. T. (1968). In Progress in the Chemistry of Fats and Other Lipids, pp. 9, 275 [R. T. Holman, editor]. Oxford: Pergamon Press.

Holman, R. T., Johnson, S. B., Mercuri, O., Itarte, H. J., Rodrigo, M. A. \& De Tomas, M. E. (1981). Am. F. clin. Nutr. 34, I 534 .

Holub, B. J. (1982). Adv. Nutr. Res. 4, 107.

Hoppel, C., DiMarco, J. P. \& Tandler, B. (1979). F. biol. Chem. 254, 4164 .

Horwitt, M. K. (1972). In International Symposium on Vitamin E, p. 45 [N. Shimazono and Y. Takagi, editors]. Tokyo: Kyoritzu Shuppan.

James, W. P. T. (1977). Proc. R. Soc. Med. 70, 611.

Jeffcoat, R. (r 979). Essays Biochem. 15, I.

Katz, M. L., Stone, W. L. \& Dratz, E. A. (1978). Invest. Ophthalmol. vis. Sci. 17, 1049.

Kirschman, J. C. \& Coniglio, J. G. (1961). F. biol. Chem. 236, 2200.

Kivits, G. A. A., Galguli-Swartouw, M. A. C. R. \& Christ, E. J. (1981). Biochim. biophys. Acta $665,559$.

Kung, J. T., Mackenzie, C. G. \& T'almage, D. W. (1979). Cell. Immunol. 48, 100.

Lawes, J. B. \& Gilbert, J. H. (I 860). Yl. R. agric. Soc. $21,433$.

Lawes, J. B. \& Gilbert, J. H. (1877). F. Anat. Physiol. 11, 577 .

Leat, W. M. F. (1966). Biochem. Э. 98, 598.

Leat, W. M. F., Cuthbertson, A., Howard, A. N. \& Gresham, G. A. (1964). F. agric. Sci., Camb. 63.311.

Leat, W. M. F. \& Harrison, F. A. (1972). Proc. Nutr. Soc. 31, 70 A.

Leat, W. M. F. \& Harrison, F. A. (1980). F. Dev. Physiol. 2, 257.

Leat, W. M. F., Kemp, P., Lysons, R. J. \& Alexander, T. J. L. (1977). F. agric. Sci., Camb. 88, 175.

Leat, W. M. F. \& Northrop, C. A. (1981). Q. fl. exp. Physiol. 66, 99.

Leat, W. M. F., Northrop, C. A., Harrison, F. A. \& Cox, R. W. (1983). Q. Yl. exp. Physiol. (In the Press.)

Lindsay, D. B. \& Leat, W. M. F. (1977). F. agric. Sci., Camb. 89, 2 I 5.

Mead, J. F. (1968). In Progress in the Chemistry of Fats and Other Lipids, pp. 9, 159 [R. T. Holman, editor]. Oxford: Pergamon Press.

Mohrhauer, H. \& Holman, R. T. (1963). F. Nutr. 81, 67.

Naismith, D. J. (1973). Br. Y. Nutr. 30, 567.

O'Dell, B. L., Reynolds, G. \& Reeves, P. G. (1977). F. Nutr. $107,1222$. 
Olpin, S. E. \& Bates, C. J. (1982). Br. F. Nutr. 47, 589 .

Peifer, J. J. \& Lewis, R. D. (1979). F. Nutr. I09, 2160.

Rivers, J. P. W., Sinclair, A. J. \& Crawford, M. A. (1975). Nature, Lond. $25^{8}$, 171.

Sinclair, A. J., McLean, J. G. \& Monger, E. A. (1979). Lipids I 4, 932.

Tappel, A. L. (1962). Vitams. Horm. 20, 493.

Tappel, A. L., Fletcher, B. \& Deamer, D. (1973). F. Gerontol. 28, 415.

Taylor, M. \& Thomke, S. (1964). Nature, Lond. $201,1246$.

Tinoco, J., Miljanich, P. \& Medwadowski, B. (1977). Biochim. biophys. Acta 486, 575.

Underwood, E. J. (1977). In Trace Elements in Human and Animal Nutrition, 4th ed., p. 2 I4. London and New York: Academic Press.

Volpe, J. J. \& Marasa, J. C. (1978). Y. Neurochem. 30, 975.

Volpe, J. J. \& Vagelos, P. R. (I976). Physiol. Rev. 56, 339.

Wahle, K. W. J. \& Davies, N. T. (1975). Br. J. Nutr. 34, 105.

Whitehead, C. C. \& Bannister, D. W. (1978). Br. F. Nutr. 39, 547.

Wight, P. A. L. \& Siller, W. G. (1975). Res. vet. Sci. 19, 173.

Williams, J. N. Jr. \& Hurlebaus, A. J. (1966). J. Nutr. 89, 477.

Witten, P. W. \& Holman, R. T. (1952). Archs. Biochem. Biophys. 41, 266.

Witting, L. A. (1974). Y. Am. clin. Nutr. 27, 952.

Zeisel, S. H. (1981). Ann. Rev. Nutr. 1, 95 . 